Article

\title{
Greater Height Is Associated with a Larger Carotid Lumen Diameter
}

\author{
Phoenix Hwaung ${ }^{1}$, Moonseong Heo ${ }^{2}$, Brianna Bourgeois ${ }^{1}$, Samantha Kennedy ${ }^{2}$, \\ John Shepherd ${ }^{3}$ and Steven B. Heymsfield ${ }^{1, *}$ \\ 1 Pennington Biomedical Research Center, LSU System, Baton Rouge, LA 70808, USA; \\ phoenix.hwaung@pbrc.edu (P.H.); bbou11@1suhsc.edu (B.B.) \\ 2 Department of Public Health Sciences, Clemson University, Clemson, SC 29631, USA; \\ mheo@clemson.edu (M.H.); Samantha.Kennedy@pbrc.edu (S.K.) \\ 3 University of Hawaii Cancer Center, Honolulu, HI 96813, USA; johnshep@hawaii.edu \\ * Correspondence: Steven.Heymsfield@pbrc.edu; Tel.: +1-225-763-3030
}

Received: 1 April 2019; Accepted: 13 May 2019; Published: 14 May 2019

check for updates

\begin{abstract}
Background: Previous studies link tall stature with a reduced ischemic stroke risk. One theory posits that tall people have larger cerebral artery lumens and therefore have a lower plaque occlusion risk than those who are short. Previous studies have not critically evaluated the associations between height and cerebral artery structure independent of confounding factors. Methods: The hypothesis linking stature with cerebral artery lumen size was tested in 231 adults by measuring the associations between height and common carotid artery diameter (CCAD) and intima-media thickness (IMT) after controlling for recognized vascular influencing factors (e.g., adiposity, blood pressure, plasma lipids, etc.). Results: Height remained a significant CCAD predictor across all developed multiple regression models. These models predict a $\sim 0.03 \mathrm{~mm}$ increase in CCAD for each 1-cm increase in height in this sample. This magnitude of CCAD increase with height represents over a $60 \%$ enlargement of the artery's lumen area across adults varying in stature from short $(150 \mathrm{~cm})$ to tall $(200 \mathrm{~cm})$. By contrast, IMT was non-significantly correlated with height across all developed regression models. Conclusions: People who are tall have a larger absolute CCAD than people who are short, while IMT is independent of stature. These observations potentially add to the growing cardiovascular literature aimed at explaining the lower risk of ischemic strokes in tall people.
\end{abstract}

Keywords: cerebrovascular disease; ultrasound; clinical

\section{Introduction}

There is a longstanding observation that tall people are at a lower risk of developing an ischemic stroke compared to their short counterparts [1-5]. For example, in the 1996 study by Njolstad et al. [4], an inverse dose-response association was observed between height and stroke risk in a sample of middle-aged Finnish men and women. Following adjustment for potentially confounding variables, the risk of stroke was lower by one-half in the tallest quartile of men compared to the shortest quartile of men and by two-thirds in the women. Similarly, McCarron et al. [3] reported in 2000 that subjects in the tallest quartile of their sample had a $30 \%$ and $50 \%$ lower risk of ischemic and fatal ischemic strokes, respectively, compared to those in the shortest quartile.

The mechanisms reducing the risk of stroke observed in tall people are largely unknown. Hypotheses include height-related hemodynamic [6], genetic [7], and developmental protective factors [8,9]. Reconstruction studies utilizing ex vivo experimentation combined with computational fluid dynamic techniques on the carotid artery [10], iliac artery [11], and aorta [12] may help predict 
surgical outcomes and provide quantitative insights into the resulting hemodynamic effects from directly altering vessel diameter. Very little information, however, is available on the quantitative relations between stature and cerebral artery lumen areas. One theory suggests that tall people have inherently larger arteries and can thus sustain greater plaque buildup before ischemic effects prevail $[13,14]$. The common carotid is the most accessible relevant artery for quantitative clinical assessments, although earlier studies linking height to the vessel's diameter (CCAD) often inadequately controlled for potential confounding factors. To determine whether these variables have any effects on the observed association between height and CCAD, we conducted a prospective examination of CCAD in a sample of adult men and women varying widely in age and adiposity. This study was initiated as an outgrowth of earlier investigations relating blood pressure to height in adults $[6,8,9]$.

\section{Materials and Methods}

The authors agree to make the materials reported in this study available and the senior author, whose contact information is provided, is responsible for maintaining these data sets.

\subsection{Participants}

Adult participants, aged $\geq 18$ years, were recruited as part of the National Institutes of Health Shape Up! Adults research program (R01DK109008). The sample selection was designed to represent a cross-section of the non-institutionalized adult U.S. population. Participants were excluded if they had medical implants, joint replacements, were pregnant, or surpassed the dual-energy $x$-ray (DXA) scanners weight limit of $200 \mathrm{~kg}$. The study was approved by the Pennington Biomedical Research Center Institutional Review Board. All participants signed an informed consent prior to participation.

\subsection{Measurements}

A minimum overnight fast of $10 \mathrm{~h}$ was mandatory for participation. The next morning, a medical evaluation ensured participants met study criteria. The following measurements were made on the same day by trained and certified technicians.

\subsubsection{Weight and Height}

Participants were barefoot and wore a hospital gown over undergarments. Body weight was measured three times with a digital scale (Holtain Ltd., Crymych, Dyfed, UK) and averaged to the nearest $0.1 \mathrm{~kg}$.

Participants were positioned with their heels, buttocks, and upper back in contact with the stadiometer (Holtain Ltd., Crymych, Dyfed, UK). The slide was lowered to the vertex of the participant's skull during a breath hold. Three readings were made to the nearest $0.1 \mathrm{~cm}$ and averaged. Body mass index (BMI) was calculated as weight/height ${ }^{2}$.

\subsubsection{Adiposity}

Body composition, including \%fat, was measured with the Center's DXA scanner (Horizon, Hologic, Marlborough, MA, USA). The system was regularly calibrated using the manufacturer's phantoms and protocol.

\subsubsection{Blood Pressure}

Systolic blood pressure (SBP) and diastolic blood pressure (DBP) were measured three times and averaged using appropriate cuff sizes with a previously reported standardized protocol [6]. Pulse pressure (PP) was calculated as SBP - DBP. Mean blood pressure (MBP) was calculated as (SBP + $2 \times$ DBP $) / 3$. 


\subsubsection{Blood Studies}

Fasting plasma glucose and lipids were analyzed using a Beckman Coulter UniCel ${ }^{\circledR}$ DxC600 system (Beckman Coulter Inc., Brea, CA, USA) in the center's certified clinical laboratory.

\subsubsection{Ultrasound}

Systolic and diastolic right common carotid artery diameter images were obtained in recumbent participants using a 7.5-MHz gel-coated transducer (Aplio 80, Toshiba, Otawara, Japan) and stored on the B-mode system. The system's caliper tool was used to measure the CCAD and intima-media thickness (IMT) to the nearest $0.1 \mathrm{~mm}$ at a horizontal section at least $10 \mathrm{~mm}$ in length. CCAD was measured from the intima-lumen interface of the near wall to the far vessel wall. IMT was measured from the lumen-intima to media-adventitia interface of the far vessel wall. An example scan is presented in Figure S1.

\subsection{Statistical Methods}

The statistical analyses were conducted in three stages, the first involving descriptive analyses of sample characteristics. The second stage involved exploratory development of systolic CCAD and IMT multiple regression models. The third stage included the refinement of these models to predict how CCAD and IMT vary with height and other influencing factors.

\subsubsection{Exploratory Analyses}

Analyses began with the full sample of 231 men and women. Systolic CCAD or IMT were set as dependent variables in multiple regression models with sex, age, height, plasma glucose and lipids, and blood pressure set as potential covariates. To confirm the strength of the initial observations related to stature, we then ran these analyses on a subgroup of 156 participants ( 93 women) who had no history of chronic disease, were not smokers, and were not taking lipid or blood pressure-lowering medicines. We present these analyses as Models 1 and 2 for CCAD and IMT, respectively. Total cholesterol, MBP, and PP were not included in these models because of potential collinearity.

\subsubsection{Main Model Development}

Prediction equations were developed describing variation in systolic CCAD and IMT with height as might be observed in the general U.S. population using our full sample of 231 participants. These two models (CCAD, Model 3; IMT, Model 4) were prepared using standard mixed stepwise multiple regression analysis and confirmed using 10-fold cross-validation and cross-validation error (CVE). In Models 5 and 6, we replaced BMI with \%fat using the same sample tested in Models 3 and 4.

\subsubsection{Sensitivity Analyses}

Models 7 through 9 include lipid covariates; therefore, these regression analyses were carried out after excluding participants currently taking lipid-lowering medicines $(n=28)$. None of the blood pressure covariates entered CCAD or IMT prediction models, and these results are not presented.

All statistical evaluations were conducted in JMP (SAS Institute Inc., Cary, NC, USA) with demographic and other baseline results presented as mean \pm standard deviation. Standard errors (SEs) are presented for all of the regression models. The regression model variables were all normally distributed and model interaction terms were non-significant. Between-sex differences in demographic variables were tested using unpaired t-tests and $p<0.05$ was considered a statistically significant difference. The internal carotid artery area was calculated by assuming the vessel lumen is circular (i.e., area $\left.=\pi(\mathrm{CCAD} / 2)^{2}\right)$. 


\section{Results}

\subsection{Descriptive Analyses}

The clinical characteristics and medical history of the 231 participants enrolled in the study are shown in Table 1 . The sample included 101 men and 130 women ranging in age from 18 to 75 years (mean, $47 \pm 17$ years) and BMI from 16.0 to $52.6 \mathrm{~kg} / \mathrm{m}^{2}\left(27.9 \pm 6.8 \mathrm{~kg} / \mathrm{m}^{2}\right)$.

Table 1. Subject characteristics.

\begin{tabular}{|c|c|c|c|}
\hline & Men & Women & Total \\
\hline $\mathbf{N}$ & 101 & 130 & 231 \\
\hline Age (years) & $45.7 \pm 17.7$ & $47.7 \pm 17.0$ & $46.8 \pm 17.3$ \\
\hline Weight (kg) & $90.2 \pm 21.8$ & $72.3 \pm 19.2 \ddagger$ & $80.1 \pm 22.2$ \\
\hline Height (cm) & $177.3 \pm 6.9$ & $162.4 \pm 6.6 \ddagger$ & $168.9 \pm 10.0$ \\
\hline BMI $\left(\mathrm{kg} / \mathrm{m}^{2}\right)$ & $28.6 \pm 6.3$ & $27.4 \pm 7.1$ & $27.9 \pm 6.8$ \\
\hline$\%$ Fat & $26.3 \pm 6.3$ & $37.9 \pm 7.5 \ddagger$ & $32.9 \pm 9.1$ \\
\hline CCAD $(\mathrm{mm})$ & $6.16 \pm 0.88$ & $5.72 \pm 0.79 \ddagger$ & $5.92 \pm 0.85$ \\
\hline IMT (mm) & $0.66 \pm 0.20$ & $0.64 \pm 0.20$ & $0.65 \pm 0.20$ \\
\hline Plasma Glucose (mg/dL) & $96.3 \pm 20.2$ & $94.7 \pm 18.8$ & $95.4 \pm 19.4$ \\
\hline $\mathrm{TG}(\mathrm{mg} / \mathrm{dL})$ & $97.5 \pm 63.0$ & $86.6 \pm 46.6$ & $91.32 \pm 54.5$ \\
\hline LDL (mg/dL ) & $104.9 \pm 30.1$ & $112.7 \pm 30.3$ & $109.3 \pm 30.4$ \\
\hline HDL (mg/dL) & $53.4 \pm 14.3$ & $63.5 \pm 16.7 \ddagger$ & $59.1 \pm 16.5$ \\
\hline $\mathrm{TC}(\mathrm{mg} / \mathrm{dL})$ & $177.8 \pm 37.4$ & $193.8 \pm 38.3 \ddagger$ & $186.8 \pm 38.7$ \\
\hline SBP (mmHg) & $119.2 \pm 12.8$ & $116.6 \pm 15.2$ & $117.7 \pm 14.2$ \\
\hline DBP (mmHg) & $77.9 \pm 8.3$ & $73.9 \pm 8.8 \ddagger$ & $75.6 \pm 8.8$ \\
\hline PP (mmHg) & $41.3 \pm 9.6$ & $42.7 \pm 11.4$ & $42.1 \pm 10.7$ \\
\hline MBP (mmHg) & $91.6 \pm 0.89$ & $88.1 \pm 0.87^{\dagger}$ & $89.7 \pm 0.64$ \\
\hline Medical History & & & Total \\
\hline Blood Pressure (BP) & & & 47 \\
\hline Only BP & & & 22 \\
\hline +Chol & & & 11 \\
\hline +Diabetes & & & 8 \\
\hline +Chol and Diabetes & & & 4 \\
\hline Cholesterol (Chol) & & & 28 \\
\hline Only Chol & & & 8 \\
\hline +Diabetes & & & 2 \\
\hline Type II Diabetes & & & 26 \\
\hline Only Diabetes & & & 7 \\
\hline Heart Disease & & & 5 \\
\hline Only Heart Disease & & & 0 \\
\hline +Diabetes & & & 3 \\
\hline +BP and Chol & & & 1 \\
\hline +Diabetes, BP, and Chol & & & 1 \\
\hline Current Smokers & & & 17 \\
\hline Only Smokers & & & 15 \\
\hline$+\mathrm{BP}$ & & & 1 \\
\hline +Diabetes & & & 1 \\
\hline
\end{tabular}

Characteristics of the total sample of men and women, expressed as $\mathrm{X} \pm \mathrm{SD}$. Abbreviations: $\mathrm{BP}$, participants taking blood pressure medication; BMI, body mass index; CCAD, common carotid artery diameter in systole; Chol, participants taking cholesterol-lowering medications; DBP, diastolic blood pressure; HDL, high-density lipoprotein cholesterol; IMT, carotid intima-media thickness in systole; LDL, low-density lipoprotein cholesterol; MBP, mean blood pressure; PP, pulse pressure; SBP, systolic blood pressure; TC, total cholesterol; plasma TG, triglycerides. ${ }^{\dagger}, p<0.01 ;{ }^{\ddagger}, p<0.001$ versus men. 
Men and women were similar in age, on average in the fifth decade, and generally overweight (i.e., BMI $\geq 25 \mathrm{~kg} / \mathrm{m}^{2}$ ). Overall, women had a significantly smaller mean CCAD, body weight, height, $\mathrm{MBP}$, and DBP, and significantly larger total and high-density lipoprotein-cholesterol, and \%fat levels than the men.

\subsection{Exploratory Analyses}

CCAD positively correlated with height before controlling for potential covariates (Figure 1), and was significantly correlated with height after controlling for potential covariates in the full sample $\left(p<10^{-5}\right)$ of 231 participants and in the smaller sample $(p=0.00022)$ of 156 clinically healthy participants (Model 1, Table 2). BMI ( $p=0.0053$ ) was also a significant covariate in Model 1. In Model 2 for IMT, only age $(p=0.0008)$ entered as a significant covariate; height ( $p=0.12)$ was non-significant, which is also shown in Figure 1.

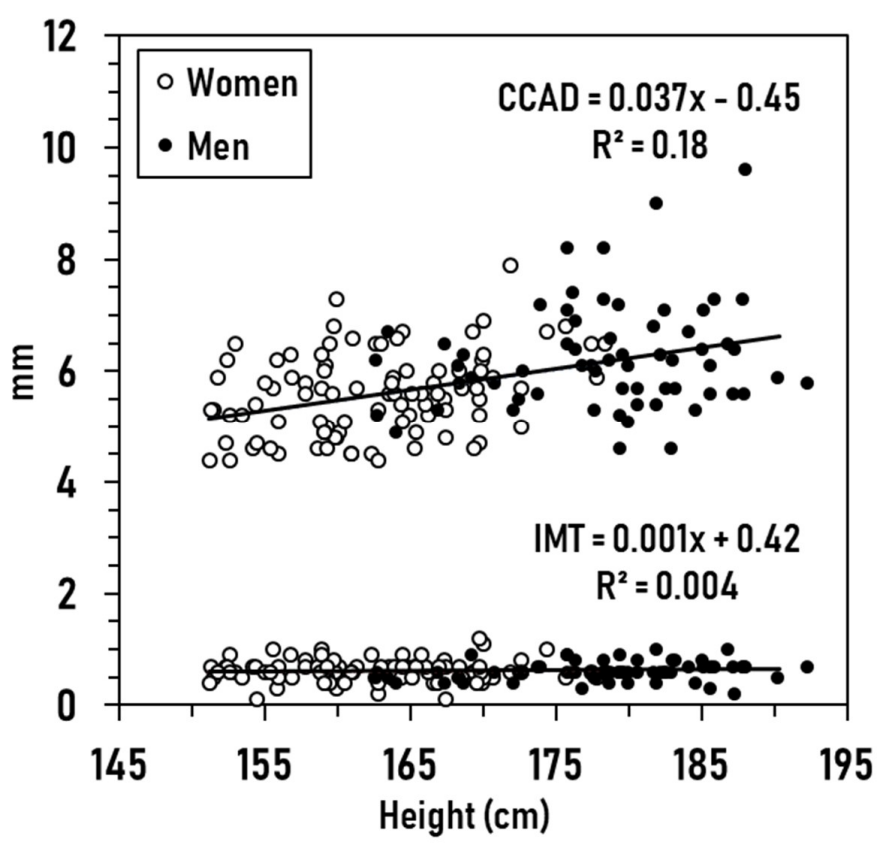

Figure 1. Measured CCAD $(\mathrm{mm})$ and IMT $(\mathrm{mm})$ in men and women versus height $(\mathrm{cm})$. The CCAD correlation is significant at $p<0.001$, while the IMT correlation is non-significant $(p=0.41)$.

Table 2. Right common carotid artery diameter (CCAD) and intima-media thickness (IMT) multiple regression models $(n=156)$.

\begin{tabular}{|c|c|c|c|c|c|c|}
\hline \multirow[b]{2}{*}{ Covariate } & \multicolumn{3}{|c|}{ Model 1: CCAD } & \multicolumn{3}{|c|}{ Model 2: IMT } \\
\hline & B & $95 \%$ CI & SE & B & $95 \%$ CI & SE \\
\hline Intercept & -0.62 & -4.25 to 3.00 & 1.84 & -0.29 & -1.09 to 0.51 & 0.41 \\
\hline Height (cm) & $0.035 \ddagger$ & 0.017 to 0.053 & 0.009 & 0.003 & -0.001 to 0.007 & 0.002 \\
\hline BMI $\left(\mathrm{kg} / \mathrm{m}^{2}\right)$ & $0.047^{\dagger}$ & 0.014 to 0.080 & 0.017 & 0.004 & -0.003 to 0.011 & 0.004 \\
\hline Age (years) & 0.007 & -0.003 to 0.016 & 0.005 & $0.004^{\ddagger}$ & 0.002 to 0.006 & 0.001 \\
\hline $\operatorname{Sex}(0, F ; 1, M)$ & 0.172 & -0.40 to 0.74 & 0.289 & -0.041 & -0.167 to 0.086 & 0.064 \\
\hline$\%$ Fat & 0.009 & -0.020 to 0.039 & 0.015 & 0.0002 & -0.006 to 0.007 & 0.003 \\
\hline PGlu (mg/dL) & -0.004 & -0.022 to 0.014 & 0.009 & 0.002 & -0.002 to 0.006 & 0.002 \\
\hline TG (mg/dL) & 0.001 & -0.002 to 0.004 & 0.001 & 0.00008 & -0.0005 to 0.0006 & 0.0003 \\
\hline LDL (mg/dL) & -0.005 & -0.010 to 0.0001 & 0.003 & 0.0003 & -0.001 to 0.001 & 0.0006 \\
\hline HDL (mg/dL) & 0.005 & -0.004 to 0.013 & 0.004 & -0.0003 & -0.002 to 0.002 & 0.001 \\
\hline SBP (mmHg) & -0.002 & -0.016 to 0.011 & 0.007 & 0.0003 & -0.003 to 0.003 & 0.002 \\
\hline DBP (mmHg) & -0.008 & -0.029 to 0.013 & 0.011 & -0.002 & -0.007 to 0.003 & 0.002 \\
\hline$R^{2}$ & & $0.27 \ddagger$ & 0.77 & & $0.13 \ddagger$ & 0.17 \\
\hline
\end{tabular}

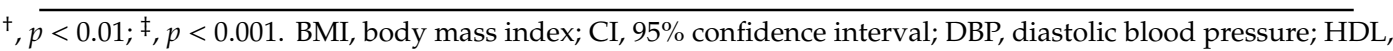
high-density lipoprotein cholesterol; IMT, carotid intima-media thickness in systole; LDL, low-density lipoprotein cholesterol; PGlu, plasma glucose; SBP, systolic blood pressure; SE, standard error. 


\subsection{Prediction Models}

The prediction equations developed from the stepwise selection for CCAD (Model 3) and IMT (Model 4) are summarized in Table S1 and were as follows:

$$
\begin{gathered}
\operatorname{CCAD}(\mathrm{mm})=-0.258+0.029 \times \text { Height }(\mathrm{cm})+0.006 \times \text { Age }(\text { years })+0.036 \times \mathrm{BMI}\left(\mathrm{kg} / \mathrm{m}^{2}\right) \\
\text { with an } R^{2} \text { of } 0.20(\mathrm{SE}, \pm 0.77, p<0.001 ; \mathrm{CVE}, \pm 0.04), \text { and } \\
\begin{aligned}
\mathrm{IMT}(\mathrm{mm})=0.25+0.005 \times \text { Age }(\text { years })+0.005 \times \mathrm{BMI}\left(\mathrm{kg} / \mathrm{m}^{2}\right) \\
\text { with an } R^{2} \text { of } 0.24(\mathrm{SE}, \pm 0.18, p<0.001) .
\end{aligned}
\end{gathered}
$$

Equation (1) indicates that CCAD increases $\sim 0.03 \mathrm{~mm}$ for each 1-cm increase in height; IMT is not influenced by height as indicated by Equation (2).

\subsection{Sensitivity Analyses}

Replacing BMI with \%fat in the CCAD model led to sex becoming a significant predictor in place of age; height remained a significant predictor of CCAD and not IMT (Models 5 and 6, Table S2). Total and low-density lipoprotein-cholesterol entered as individual predictor variables for CCAD among participants who were not taking lipid-lowering medicines. (Models 7-9, Table S3).

Across all of the developed models (Table 2 and Table S1-S3) height remained a relatively stable predictor of CCAD of about $0.03 \mathrm{~mm} / \mathrm{cm}$ and was consistently non-significantly correlated with IMT.

\subsection{Model Integration}

The three main CCAD and IMT predictors presented in Equations (1) and (2) show variable effects of height, age, and BMI on carotid artery structure as descriptively shown in Figure 2. The reference person is 20 years old, of normal weight (BMI, $\left.20 \mathrm{~kg} / \mathrm{m}^{2}\right)$, and short $(150 \mathrm{~cm}$ or about $5 \mathrm{ft}$ ). Increasing this person's height to $200 \mathrm{~cm}$, or about $6.5 \mathrm{ft}$, leads to a $67 \%$ increase in the carotid's internal lumen area but no change in IMT. Increasing age to 70 years leads to a $13 \%$ increase in the carotid's internal lumen area and a $56 \%$ increase in IMT. Lastly, moving BMI into the obese range $\left(35 \mathrm{~kg} / \mathrm{m}^{2}\right)$ increases the carotid's internal lumen area by $23 \%$ and IMT by $17 \%$. Therefore, the effects of variable height on carotid cross-sectional structure are different from those of BMI and age, with the latter two influencing IMT in addition to CCAD.

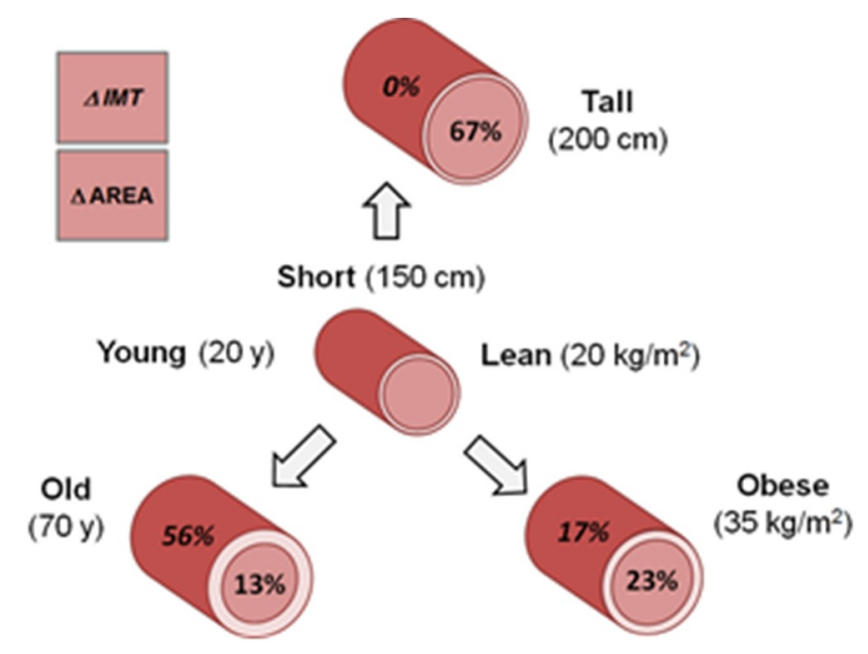

Figure 2. Hypothetical cross-sections of the common carotid artery showing the estimated percentage differences in internal lumen areas and intima-media thicknesses between a short, young, normal (Nl) weight reference person and their tall, old, and obese counterparts. Calculations are based on respective CCAD and IMT prediction equations \#1 and \#2 in the text and Table S1. 


\section{Discussion}

\subsection{Height and Carotid Artery Structure}

Prompted by reports spanning several decades relating adult height to stroke risk [1-5], we embarked on the current project to test the often-stated contention that tall people have relatively larger cerebral artery diameters than short people. While arteries likely scale in size with height, an intuition confirmed by previous studies [15,16], a critical test of this hypothesis for the clinically accessible CCAD was lacking as other potential lumen size determinants were largely uncontrolled for. Earlier reports focused mainly on well-established anatomic vascular risk factors such as the carotid's IMT [17,18] and external diameter [16], while others explored associations between lumen diameter and sex [12], age [19,20], BMI [21], or genetic factors [22,23].

The findings reported herein show that the positive association between CCAD and height in adults is so robust that it remains significant even after controlling for age, BMI, adiposity, and other potential covariates including plasma glucose and lipid levels, and brachial artery blood pressures. Additionally, our findings indicate that IMT is not significantly correlated with stature, suggesting that overall vascular characteristics are distinctly influenced by adult height and differ from those of age and BMI, two well-studied major carotid artery structural determinants.

These observations provide additional support to earlier reports relating greater height with larger levels of whole-body oxygen consumption, cardiac output, and left ventricular mass [24-26]. People who are tall also have lower brachial artery systolic and pulse pressures after the age of 40 years relative to those who are short, an effect that likely derives from hemodynamic and hydrostatic mechanisms [6,27]. A combination of metabolic, hemodynamic, and hydrostatic effects may account for the observed greater CCAD but unchanged IMT with increasing height. The relative contributions of these multiple stature-related physiological effects to carotid artery structure need to be quantitatively evaluated in future studies.

Clinical observations also link height with coronary and carotid artery pathology and mortality risk. In a widely cited study, Nwasokwa et al. [14] observed a higher prevalence and greater severity of coronary artery disease in short men undergoing cardiac catheterization than in their tall counterparts. O'Conner et al. observed a significantly increased in-hospital mortality risk in patients undergoing coronary artery bypass grafts who had a small left anterior descending coronary artery diameter [28]. Fisher et al. found that small physical size and related small coronary artery diameter predicted post-operative bypass graft mortality, even after controlling for other risk factors [29]. Excess operative mortality in women undergoing coronary artery surgery was postulated by the authors as secondary to their smaller stature and coronary artery diameters. Small body size, as defined by height, is a risk factor for perioperative stroke and death in women undergoing carotid endarterectomy [13].

\subsection{Height and Other Vascular Structures}

Previous studies report significant height associations with the diameters of other vascular structures such as the aorta [30-32], left ventricle [33], common femoral artery [34,35], main pulmonary artery [36], mid-left descending coronary artery [14,28], and popliteal artery [37]. The effects of height on vascular structure thus go well beyond the carotid artery with stature appearing to influence multiple cardiovascular system components. By inference, cerebral arteries distal to the common carotid are also larger in people who are tall than in those who are short.

\subsection{Age and Adiposity Effects on Carotid Structure}

This study confirms the positive correlation between age and IMT observed in previous studies [38]. The effects of adult age on CCAD reported in previous studies are less clear with responses ranging from an increase $[19,20]$ to no change [39] in lumen diameter, discrepant observations that may be due to differences in participant sample size or age range. The reported increase in CCAD with greater age may be secondary to endogenous physiological mechanisms that favor enlargement of 
the arterial lumen $[20,40,41]$. In the current study, we observed a significant correlation between age and CCAD after controlling for height and BMI, although this association weakened in our clinically healthy subgroup.

As with other reports, we also confirmed an increase in both CCAD and IMT as a function of BMI $[17,42,43]$, and more specifically, adiposity as defined by \%fat. Kappus et al. attributed these vascular effects to an adiposity-related increase in blood pressure, notably that of the carotid artery [21,44]. In a previous study, we also observed a significant correlation between mean brachial artery blood pressure and BMI in non-hypertensive adults in the USA population [6]. Importantly, in the current study, height remained a significant predictor of CCAD, independent of both age and BMI in all of the models tested.

\subsection{Study Limitations}

Our sample size was relatively small, particularly when we excluded participants in subgroup analyses. While our findings related to height and CCAD were robust, we cannot exclude subtle covariate effects (e.g., race, physical activity level, etc.) or interaction effects that might be discerned with greater study power. We were also unable to directly measure local carotid blood pressure, which previous studies suggest may be a better predictor of carotid physiology compared to peripheral blood pressure measurements [38,45]. Additionally, we made the assumption that the cross-section of the carotid artery is circular in shape. Analyzing the associations between height and carotid artery blood velocity, blood viscosity, or elasticity may help to elucidate possible mechanisms through which stature affects vascular properties.

\section{Conclusions}

In conclusion, we critically tested the hypothesis that the carotid artery's luminal diameter is significantly associated with adult stature. This theory was prompted by the often stated but not critically tested assertion that tall people are at a lower risk of experiencing an occlusive ischemic stroke than people who are short because they have larger cerebral artery lumens. We confirmed this hypothesis, demonstrating that the carotid's lumen increases with height. These findings suggest that arteries with larger lumens in general supply the central nervous system in people who are tall relative to those who are short. These and related blood pressure and clinical observations [6] suggest that height plays a more important role in cardiovascular physiology and pathology than previously recognized.

Supplementary Materials: The following are available online at http://www.mdpi.com/2305-6320/6/2/57/s1, Table S1: Common carotid artery diameter (CCAD) and intima-media thickness (IMT) core prediction models $(\mathrm{n}=231)$, Table S2: Common carotid artery diameter (CCAD) and intima-media thickness (IMT) core prediction models replacing BMI with \%fat as a covariate $(n=231)$, Table S3: Common carotid diameter (CCAD) and intima-media thickness (IMT) prediction models including lipid analyses $(n=203)$, Figure S1: Ultrasound scan with carotid artery diameter (CCAD) and intima-media thickness (IMT).

Author Contributions: Conceptualization, P.H., B.B. and S.B.H.; methodology, B.B., P.H., S.B.H.; software, M.H., J.S.; validation, P.H., M.H., B.B., S.K., J.S., S.B.H.; formal analysis, P.H., B.B., S.K., J.S. and S.B.H.; investigation, P.H., B.B., S.K., J.S. and S.B.H.; resources, S.B.H, J.S.; data curation, P.H., M.H.; writing-original draft preparation, P.H., S.K., M.H., J.S. and S.B.H.; writing-review and editing, P.H., B.B., S.K., M.H., J.S. and S.B.H.; supervision, J.S.; S.B.H.; project administration, S.B.H.; funding acquisition, J.S., S.B.H.

Funding: This research was funded by NATIONAL INSTITUTES OF HEALTH NORC CENTER GRANTS, P30DK072476, Pennington/Louisiana; and P30DK040561, Harvard; and R01DK109008, Shape UP! Adults.

Acknowledgments: The authors extend their appreciation to Melanie Peterson for her assistance with manuscript preparation.

Conflicts of Interest: The authors declare no conflict of interest. The funding agencies were not involved in the design of the study; in the collection, analyses or interpretation of data; in the writing of the manuscript, or in the decision to publish the results. 


\section{References}

1. Emerging Risk Factors Collaboration. Adult height and the risk of cause-specific death and vascular morbidity in 1 million people: Individual participant meta-analysis. Int. J. Epidemiol. 2012, 41, 1419-1433. [CrossRef]

2. Goldbourt, U.; Tanne, D. Body height is associated with decreased long-term stroke but not coronary heart disease mortality? Stroke 2002, 33, 743-748. [CrossRef]

3. McCarron, P.; Greenwood, R.; Ebrahim, S.; Elwood, P.; Smith, G.D. Adult height is inversely associated with ischaemic stroke. The Caerphilly and Speedwell collaborative studies. J. Epidemiol. Community Health 2000, 54, 239-240. [CrossRef]

4. Njolstad, I.; Arnesen, E.; Lund-Larsen, P.G. Body height, cardiovascular risk factors, and risk of stroke in middle-aged men and women: A 14-year follow-up of the Finnmark Study. Circulation 1996, 94, 2877-2882. [CrossRef]

5. Nuesch, E.; Dale, C.; Palmer, T.M.; White, J.; Keating, B.J.; van Iperen, E.P.; Goel, A.; Padmanabhan, S.; Asselbergs, F.W.; Investigators, E.P.-N.; et al. Adult height, coronary heart disease and stroke: A multi-locus Mendelian randomization meta-analysis. Int. J. Epidemiol. 2016, 45, 1927-1937. [CrossRef] [PubMed]

6. Bourgeois, B.; Watts, K.; Thomas, D.M.; Carmichael, O.; Hu, F.B.; Heo, M.; Hall, J.E.; Heymsfield, S.B. Associations between height and blood pressure in the United States population. Medicine 2017, 96, e9233. [CrossRef] [PubMed]

7. Nelson, C.P.; Hamby, S.E.; Saleheen, D.; Hopewell, J.C.; Zeng, L.; Assimes, T.L.; Kanoni, S.; Willenborg, C.; Burgess, S.; Amouyel, P.; et al. Genetically determined height and coronary artery disease. N. Engl. J. Med. 2015, 372, 1608-1618. [CrossRef]

8. Korhonen, P.E.; Kautiainen, H.; Eriksson, J.G. The shorter the person, the higher the blood pressure: A birth cohort study. J. Hypertens. 2017, 35, 1170-1177. [CrossRef]

9. Langenberg, C.; Hardy, R.; Kuh, D.; Wadsworth, M.E. Influence of height, leg and trunk length on pulse pressure, systolic and diastolic blood pressure. J. Hypertens. 2003, 21, 537-543. [CrossRef]

10. Polanczyk, A.; Podgorski, M.; Wozniak, T.; Stefanczyk, L.; Strzelecki, M. Computational fluid dynamics as an engineering tool for the reconstruction of hemodynamics after carotid artery stenosis operation: A case Study. Medicina 2018, 54, 42. [CrossRef] [PubMed]

11. Polanczyk, A.; Klinger, M.; Nanobachvili, J.; Huk, I.; Neumayer, C. Artificial circulatory model for analysis of human and artificial vessels. Appl. Sci. 2018, 8, 1017. [CrossRef]

12. Polanczyk, A.; Piechota-Polanczyk, A.; Domenig, C.; Nanobachvili, J.; Huk, I.; Neumayer, C. Computational fluid dynamic accuracy in mimicking changes in blood hemodynamics in patients with acute type IIIb aortic dissection treated with TEVAR. Appl. Sci. 2018, 8, 1309. [CrossRef]

13. Messe, S.R.; Kasner, S.E.; Mehta, Z.; Warlow, C.P.; Rothwell, P.M. Effect of body size on operative risk of carotid endarterectomy. J. Neurol. Neurosurg. Psychiatry 2004, 75, 1759-1761. [CrossRef]

14. Nwasokwa, O.N.; Weiss, M.; Gladstone, C.; Bodenheimer, M.M. Higher prevalence and greater severity of coronary disease in short versus tall men referred for coronary arteriography. Am. Heart J. 1997, 133, 147-152. [CrossRef]

15. Krejza, J.; Arkuszewski, M.; Kasner, S.E.; Weigele, J.; Ustymowicz, A.; Hurst, R.W.; Cucchiara, B.L.; Messe, S.R. Carotid artery diameter in men and women and the relation to body and neck size. Stroke 2006, 37, 1103-1105. [CrossRef]

16. Polak, J.F.; Kronmal, R.A.; Tell, G.S.; O’Leary, D.H.; Savage, P.J.; Gardin, J.M.; Rutan, G.H.; Borhani, N.O. Compensatory increase in common carotid artery diameter: Relation to blood pressure and artery intima-media thickness in older adults. Stroke 1996, 27, 2012-2015. [CrossRef]

17. Litwin, M.; Trelewicz, J.; Wawer, Z.; Antoniewicz, J.; Wierzbicka, A.; Rajszys, P.; Grenda, R. Intima-media thickness and arterial elasticity in hypertensive children: Controlled study. Pediatr. Nephrol. 2004, 19, 767-774. [CrossRef]

18. Sturm, W.; Sandhofer, A.; Engl, J.; Laimer, M.; Molnar, C.; Kaser, S.; Weiss, H.; Tilg, H.; Ebenbichler, C.F.; Patsch, J.R. Influence of visceral obesity and liver fat on vascular structure and function in obese subjects. Obesity 2009, 17, 1783-1788. [CrossRef] 
19. Chien, C.Y.; Liu, C.C.; Po, H.L.; Yen, C.H.; Hou, C.J.; Kuo, J.Y.; Hung, C.L.; Wang, S.S.; Yeh, H.I.; Lam, C.S. The Relationship among carotid artery remodeling, cardiac geometry, and serum N-Terminal pro-B-Type natriuretic peptide level in asymptomatic asians: Sex-differences and longitudinal GEE study. PLoS ONE 2015, 10, e0131440. [CrossRef]

20. Samijo, S.K.; Willigers, J.M.; Barkhuysen, R.; Kitslaar, P.J.; Reneman, R.S.; Brands, P.J.; Hoeks, A.P. Wall shear stress in the human common carotid artery as function of age and gender. Cardiovasc. Res. 1998, 39, 515-522. [CrossRef]

21. Kozakova, M.; Palombo, C.; Morizzo, C.; Hojlund, K.; Hatunic, M.; Balkau, B.; Nilsson, P.M.; Ferrannini, E. Obesity and carotid artery remodeling. Nutr. Diabetes 2015, 5, e177. [CrossRef]

22. Bella, J.N.; Cole, S.A.; Laston, S.; Almasy, L.; Comuzzie, A.; Lee, E.T.; Best, L.G.; Fabsitz, R.R.; Howard, B.V.; Maccluer, J.W.; et al. Genome-wide linkage analysis of carotid artery lumen diameter: The strong heart family study. Int. J. Cardiol. 2013, 168, 3902-3908. [CrossRef] [PubMed]

23. North, K.E.; MacCluer, J.W.; Devereux, R.B.; Howard, B.V.; Welty, T.K.; Best, L.G.; Lee, E.T.; Fabsitz, R.R.; Roman, M.J. Heritability of carotid artery structure and function: The Strong Heart Family Study. Arterioscler. Thromb. Vasc. Biol. 2002, 22, 1698-1703. [CrossRef]

24. De Simone, G.; Daniels, S.R.; Devereux, R.B.; Meyer, R.A.; Roman, M.J.; de Divitiis, O.; Alderman, M.H. Left ventricular mass and body size in normotensive children and adults: Assessment of allometric relations and impact of overweight. J. Am. Coll. Cardiol. 1992, 20, 1251-1260. [CrossRef]

25. Katori, R. Normal cardiac output in relation to age and body size. Tohoku. J. Exp. Med. 1979, 128, $377-387$. [CrossRef]

26. Lundell, B.P.; Casas, M.L.; Wallgren, C.G. Oxygen consumption in infants and children during heart catheterization. Pediatr. Cardiol. 1996, 17, 207-213. [CrossRef]

27. Fujishiro, K.; Yoshimura, S. Haemodynamic changes in carotid blood flow with age. Jikeikai. Med. J. 1982, 29, 125-138.

28. O'Connor, N.J.; Morton, J.R.; Birkmeyer, J.D.; Olmstead, E.M.; O'Connor, G.T. Effect of coronary artery diameter in patients undergoing coronary bypass surgery. Circulation 1996, 93, 652-655. [CrossRef] [PubMed]

29. Fisher, L.D.; Kennedy, J.W.; Davis, K.B.; Maynard, C.; Fritz, J.K.; Kaiser, G.; Myers, W.O. Association of sex, physical size, and operative mortality after coronary artery bypass in the Coronary Artery Surgery Study (CASS). J. Thorac. Cardiovasc. Surg. 1982, 84, 334-341. [PubMed]

30. Reed, C.M.; Richey, P.A.; Pulliam, D.A.; Somes, G.W.; Alpert, B.S. Aortic dimensions in tall men and women. Am. J. Cardiol. 1993, 71, 608-610. [CrossRef]

31. Svensson, L.G.; Kim, K.H.; Lytle, B.W.; Cosgrove, D.M. Relationship of aortic cross-sectional area to height ratio and the risk of aortic dissection in patients with bicuspid aortic valves. J. Thorac. Cardiov. Sur. 2003, 126, 892-893. [CrossRef]

32. Vasan, R.S.; Larson, M.G.; Benjamin, E.J.; Levy, D. Echocardiographic reference values for aortic root size: The framingham heart study. J. Am. Soc. Echocardiogr. 1995, 8, 793-800. [CrossRef]

33. Nidorf, S.M.; Picard, M.H.; Triulzi, M.O.; Thomas, J.D.; Newell, J.; King, M.E.; Weyman, A.E. New perspectives in the assessment of cardiac chamber dimensions during development and adulthood. J. Am. Coll. Cardiol. 1992, 19, 983-988. [CrossRef]

34. Kroger, K.; Nettelrodt, J.; Muntsches, C.; Neudorf, U.; Feuersenger, A.; Rudofsky, G.; Schmalz, A.A. Impact of age, height, and body mass index on arterial diameters in infants and children: A model for predicting femoral artery diameters prior to cardiovascular procedures. J. Endovasc. Ther. 2004, 11, 419-423. [CrossRef]

35. Sandgren, T.; Sonesson, B.; Ahlgren, R.; Lanne, T. The diameter of the common femoral artery in healthy human: Influence of sex, age, and body size. J. Vasc. Surg. 1999, 29, 503-510. [CrossRef]

36. Ussavarungsi, K.; Whitlock, J.P.; Lundy, T.A.; Carabenciov, I.D.; Burger, C.D.; Lee, A.S. The significance of pulmonary artery size in pulmonary hypertension. Diseases 2014, 2, 243-259. [CrossRef]

37. Sandgren, T.; Sonesson, B.; Ahlgren, A.R.; Lanne, T. Factors predicting the diameter of the popliteal artery in healthy humans. J. Vasc. Surg. 1998, 28, 284-289. [CrossRef]

38. Tanaka, H.; Dinenno, F.A.; Monahan, K.D.; DeSouza, C.A.; Seals, D.R. Carotid artery wall hypertrophy with age is related to local systolic blood pressure in healthy men. Arterioscler. Thromb. Vasc. Biol. 2001, 21, 82-87. [CrossRef]

39. Roman, M.J.; Saba, P.S.; Pini, R.; Spitzer, M.; Pickering, T.G.; Rosen, S.; Alderman, M.H.; Devereux, R.B. Parallel cardiac and vascular adaptation in hypertension. Circulation 1992, 86, 1909-1918. [CrossRef] 
40. Bonithon-Kopp, C.; Touboul, P.J.; Berr, C.; Leroux, C.; Mainard, F.; Courbon, D.; Ducimetiere, P. Relation of intima-media thickness to atherosclerotic plaques in carotid arteries: The Vascular Aging (EVA) Study. Arterioscler. Thromb. Vasc. Biol. 1996, 16, 310-316. [CrossRef]

41. Irace, C.; Carallo, C.; De Franceschi, M.S.; Scicchitano, F.; Milano, M.; Tripolino, C.; Scavelli, F.; Gnasso, A. Human common carotid wall shear stress as a function of age and gender: A 12-year follow-up study. Age 2012, 34, 1553-1562. [CrossRef] [PubMed]

42. Cecelja, M.; Jiang, B.; Keehn, L.; Hussain, T.; Vieira, M.S.; Phinikaridou, A.; Greil, G.; Spector, T.D.; Chowienczyk, P. Arterial stiffening is a heritable trait associated with arterial dilation but not wall thickening: A longitudinal study in the twins UK cohort. Eur. Heart J. 2018, 39, 2282-2288. [CrossRef]

43. Mannami, T.; Baba, S.; Ogata, J. Potential of carotid enlargement as a useful indicator affected by high blood pressure in a large general population of a Japanese city: The Suita study. Stroke 2000, 31, 2958-2965. [CrossRef] [PubMed]

44. Kappus, R.M.; Fahs, C.A.; Smith, D.; Horn, G.P.; Agiovlasitis, S.; Rossow, L.; Jae, S.Y.; Heffernan, K.S.; Fernhall, B. Obesity and overweight associated with increased carotid diameter and decreased arterial function in young otherwise healthy men. Am. J. Hypertens. 2014, 27, 628-634. [CrossRef]

45. Boutouyrie, P.; Bussy, C.; Lacolley, P.; Girerd, X.; Laloux, B.; Laurent, S. Association between local pulse pressure, mean blood pressure, and large-artery remodeling. Circulation 1999, 100, 1387-1393. [CrossRef] [PubMed]

(C) 2019 by the authors. Licensee MDPI, Basel, Switzerland. This article is an open access article distributed under the terms and conditions of the Creative Commons Attribution (CC BY) license (http://creativecommons.org/licenses/by/4.0/). 